\title{
Performance of Hybrid Steel Fibers Reinforced Concrete Subjected to Air Blast Loading
}

\author{
Mohammed Alias Yusof, ${ }^{1}$ Norazman Mohamad Nor, ${ }^{1}$ Ariffin Ismail, ${ }^{2}$ Ng Choy Peng, \\ Risby Mohd Sohaimi, ${ }^{1}$ and Muhammad Azani Yahya ${ }^{1}$ \\ ${ }^{1}$ Faculty of Engineering, Universiti Pertahanan Nasional Malaysia, Kem Sungai Besi, 57000 Kuala Lumpur, Malaysia \\ ${ }^{2}$ Faculty of Defence Management and Studies, Universiti Pertahanan Nasional Malaysia, Kem Sungai Besi, \\ 57000 Kuala Lumpur, Malaysia \\ Correspondence should be addressed to Mohammed Alias Yusof; alias.yusof@yahoo.com
}

Received 14 May 2013; Revised 11 September 2013; Accepted 16 September 2013

Academic Editor: Gonang Xie

Copyright (C) 2013 Mohammed Alias Yusof et al. This is an open access article distributed under the Creative Commons Attribution License, which permits unrestricted use, distribution, and reproduction in any medium, provided the original work is properly cited.

\begin{abstract}
This paper presents the results of the experimental data and simulation on the performance of hybrid steel fiber reinforced concrete (HSFRC) and also normal reinforced concrete (NRC) subjected to air blast loading. HSFRC concrete mix consists of a combination of $70 \%$ long steel hook end fibre and also $30 \%$ of short steel hook end fibre with a volume fraction of $1.5 \%$ mix. A total of six concrete panels were subjected to air blast using plastic explosive (PE4) weighing $1 \mathrm{~kg}$ each at standoff distance of 0.3 meter. The parameters measured are mode of failure under static and blast loading and also peak overpressure that resulted from detonation using high speed data acquisition system. In addition to this simulation work using AUTODYN was carried out and validated using experimental data. The experimental results indicate that hybrid steel fiber reinforced concrete panel (HSFRC) possesses excellent resistance to air blast loading as compared to normal reinforced concrete (NRC) panel. The simulation results were also found to be close with experimental data. Therefore the results have been validated using experimental data.
\end{abstract}

\section{Introduction}

Terrorists attack on buildings and infrastructures has become a global phenomenon. In most cases, the terrorists used explosives located in vehicles and blew it up at a close distance from the target. Intensive shock waves are created by this explosion which propagates outward at supersonic velocity accompanied by heat and light that induce pressure on the structural buildings and causes significant damage to the structure and loss of life. There are a number of methods to stop the terrorist attack. One of the methods is gathering information on the terrorist and stopping the attack before it takes place; another way is to protect buildings from damage by incorporating blast resistance design and also retrofitting of the existing structure [1].

This area of research is currently receiving more attention from many structural engineers as they began to consider blast loading and also blast resistance materials in their design in order to protect important buildings and structures from such attacks. Concrete is one of the most widely used construction materials for structures because it possesses considerable mass per unit cost compared to other construction materials and has excellent fire resistance and is able to absorb large amounts of energy [2]. However, one of the disadvantages of concrete is that it has a very low resistance against tensile stress and also possesses low ductility. From previous research it was found that mechanical properties of the concrete can be improved by adding fibers into the mix. Otter and Naaman reported that the addition of fibre in the concrete has significant effect on strength and toughness of concrete [3]. The test results of Nagarkar and Tambe indicated that the compressive, split tensile, and flexural strength of concrete are increased by the addition of fibre [4].

The strengthening mechanism of fibre involves transfer of stress from matrix to the fibre by interlocking the fibers and matrices when the fibre surface is deformed. The stress is thus shared by the fibers and matrix in tension, until the matrix cracks and then the total stress is progressively 


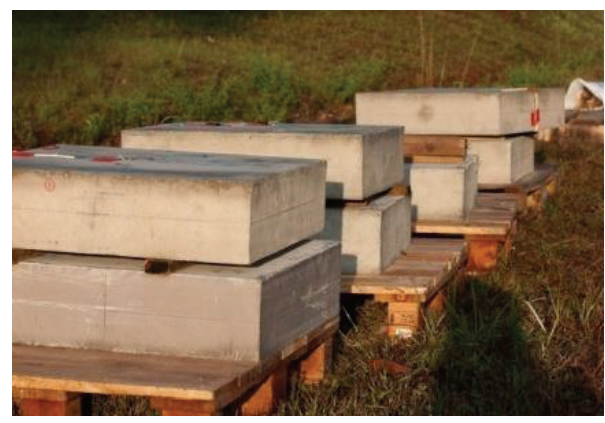

FIGURE 1: Reinforced concrete test panels.

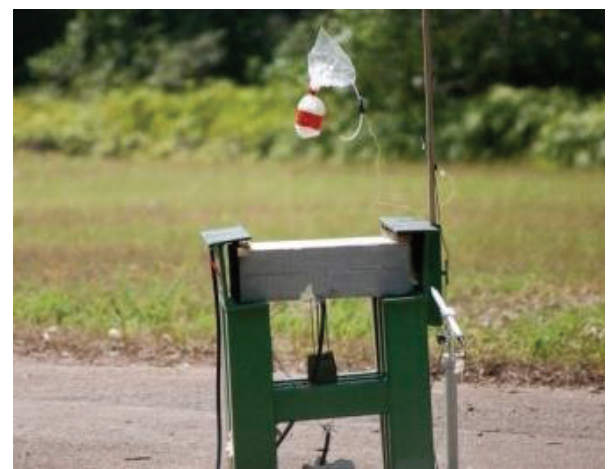

FIGURE 2: Field blast test setup.

transferred to the fibers [5]. When steel fibers reinforced beam or other structural elements are loaded, steel fibers in the matrix will bridge the cracks. The bridging action provides the steel fibre concrete with a higher ultimate tensile strength, toughness, and also energy absorption capability as compared with concrete without fibre [6].

Mohammadi et al. stated that the combination of two different fibers which are also known as hybrid fibre in a concrete mix offers more attractive engineering properties rather than single fibre [7]. Bentur and Mindess also found that hybrid steel fibers with combination of short and long fibre improved the toughness and ductility of the concrete. This is because short fibers in the concrete mix bridge the microcracks which lead to a higher tensile strength of the composite, while the long fibre arrests the propagaton of macrocracks and substantially improves the toughness and ductility of the composite [8]. Many researchers have studied the mechanical properties of hybrid steel fibre reinforced concrete. However, none of the work was done on the performance of the hybrid steel fibers reinforced concrete which is subjected to air blast loading. This research, therefore, plans to investigate the performance of hybrid steel fibers reinforced concrete subjected to air blast loading.

\section{Experiments}

2.1. Materials and Mix Proportions. In this experiment two types of concrete mixes were used which are, normal reinforced concrete (NRC) and the hybrid steel fibre reinforced

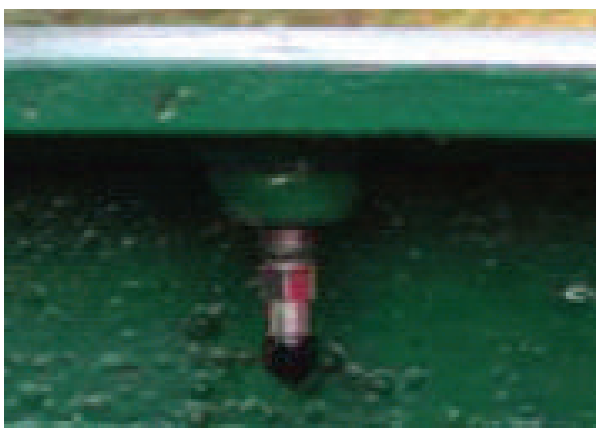

Figure 3: Pressure sensor.

concrete (HSFRC). NRC concrete consists of cement, water, aggregate, and sand, while the HSFRC is made of cement, water, aggregate, sand, and also mixture of two different lengths of hooked end steel fibers. The lengths of the fibers were $30 \mathrm{~mm}$ and $60 \mathrm{~mm}$. The steel fibers have a combination of $70 \%$ long $+30 \%$ short hooked end steel fibers with the volume fraction of $1.5 \%$. These fibers have tensile strength of $1100 \mathrm{MPa}$.

NRC and HSFRC were mixed using a proportion of cement: water: aggregate: sand at $358: 190: 1167: 752 \mathrm{~kg} / \mathrm{m}^{3}$. In the production of concrete, initially, the aggregate and sand were added into the mixer and mixed for 2 minutes and then the cement and water were poured into the mixer and mixed for another 5 minutes. At the end of the process, the fibers were added and mixed for 10 minutes. The fibers were added in small amounts to avoid fibre balling and to produce the concrete with good material consistency and workability.

The freshly mixed steel fibre reinforced concrete was poured in two equal layers of mould to cast a standard $150 \mathrm{~mm} \times 150 \mathrm{~mm} \times 150 \mathrm{~mm}$ cube and $150 \mathrm{~mm} \times 300 \mathrm{~mm}$ cylinder concrete specimen for a compressive strength test and a split tensile test. For the flexure strength test, a $100 \mathrm{~mm} \times 100 \mathrm{~mm} \times 500$ beam mould was used. Each layer was evenly vibrated for 50 seconds using a vibrating table and was left in a room temperature for 24 hours and then the specimen was removed from the mould and cured in water for 28 days.

Finally the NRC and HSFRC were poured separately into the mould of $600 \mathrm{~mm} \times 600 \mathrm{~mm} \times 150 \mathrm{~mm}$ to make them into test panels. These panels were reinforced on both tension and compression face with $10 \mathrm{~mm}$ diameter steel at $200 \mathrm{~mm}$ centre-to-centre in both ways. The NRC and HSFRC panels were later removed from the mould after consolidation and cured with wet gunny sacks for 28 days before the actual field blast test. A total of six numbers of NRC and HSFRC panels were fabricated for the blast testing.

2.2. Field Blast Testing Program. A field blast test was conducted on the NRC and also HSFRC panels to investigate the performance of the concrete panels under blast loading. The field blast was conducted at an undisclosed military facility. The concrete test panels used for the testing are shown in Figure 1. 


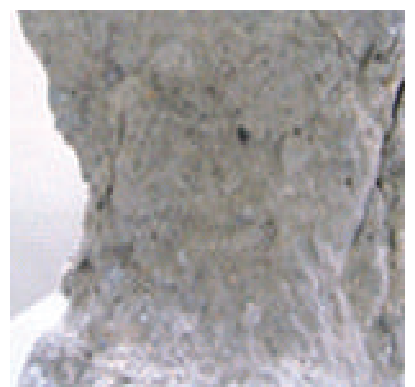

(a)

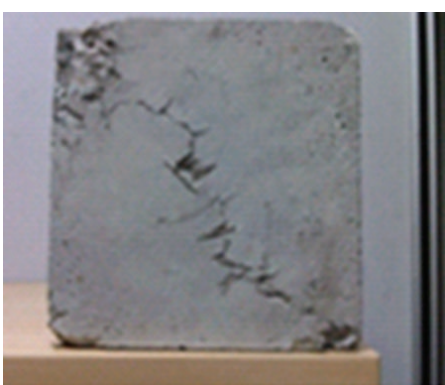

(b)

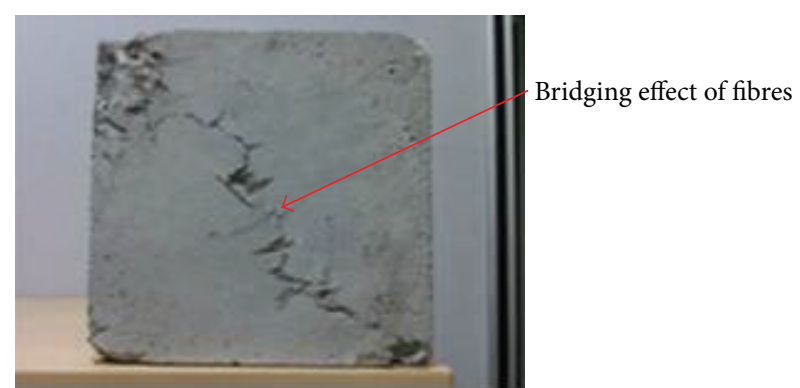

(c)

FIGURE 4: (a) Failure mode of NRC. (b) Failure mode of HSFRC. (c) Bridging effect of steel fibers in HSFRC cube.

TABLE 1: Mechanical properties of NRC and HSFRC.

\begin{tabular}{lcc}
\hline Average strength $(\mathrm{MPa})$ & NRC & HSFRC \\
\hline Compressive & 31.6 & 38.2 \\
Flexural & 4.1 & 7.7 \\
Split tensile & 3.0 & 5.0 \\
\hline
\end{tabular}

The panels were placed on the site at a proper steel frame testing rig like a table which was fabricated at the Fabrication Laboratory of the Faculty of Engineering, Universiti Pertahanan Nasional Malaysia. The size of the blast testing rig in the plan is $700 \mathrm{~mm}$, face turned towards the blast. The height of the test frame is $1000 \mathrm{~mm}$, including a $150 \mathrm{~mm}$ thick concrete base. The testing rig provides support along two sides of the specimen. The panel has been set up as a two way slab design with a span of $600 \mathrm{~mm}$. A wooden timber supporting the explosive was erected to hold the charge. Both NRC and HSFRC concrete panels were tested using $1 \mathrm{~kg}$ of plastic explosive (PE4) at a standoff distance of $300 \mathrm{~mm}$. The field blast test setup is shown in Figure 2.

In this experiment high speed data acquisition system with sampling rate up to $2 \mathrm{MHz}$ and eight hardware-timed digital I/O lines were used to measure the structural response towards blast loading. The results of the experiment were displayed using LabVIEW program. The data acquisition system and instrumentation were located inside a protected concrete building approximately 30 meters from the blast testing site. Pressure sensor was used to capture the blast peak overpressure. This sensor was fixed at the edge of the testing jig and connected via cable to the data acquisition system module. The pressure sensor is shown in Figure 3.

\section{Experimental Results and Discussion}

3.1. Mechanical Properties of Hybrid Steel Fibre. The compressive, flexural, and split tensile strength were conducted on the concrete specimens to determine the mechanical properties of the concrete mix. The test results for mechanical properties of NRC and HSFRC are shown in Table 1.

The result shows that the addition of hybrid steel fibers into the concrete mix increases the compressive, flexural, and also tensile strength of the concrete mix.

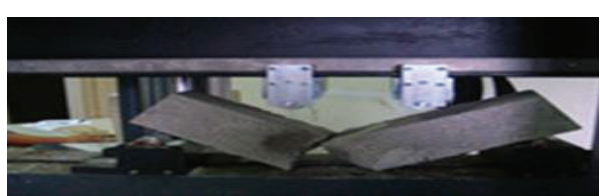

(a)

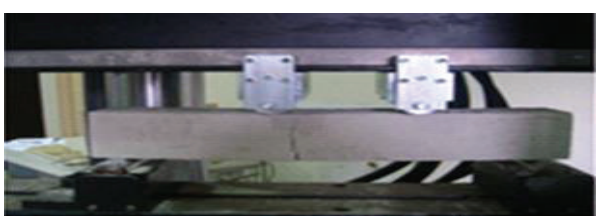

(b)

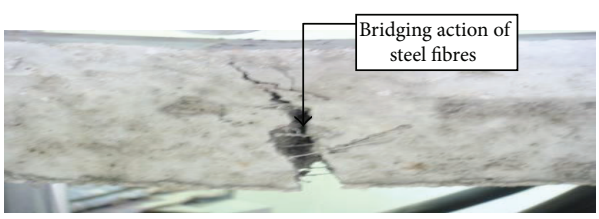

(c)

FIGURE 5: (a) Failure mode of NRC beam under flexural loading. (b) Failure mode of HSFRC beam under flexural loading. (c) Bridging action on steel fibers in the HSFRC beam.

3.2. Failure Mode of Hybrid Steel Fiber Concrete under Static Loading. The failure mode of the NRC and HSFRC concrete cubes under compression is shown in Figures 4(a) and 4(b).

From the results it was observed that the lateral surfaces for NRC mix cube as shown in Figure 4(a) split from main core and only the centre of the core remained intact. However, as for the HSFRC cubes, as shown in Figure 4(b), the lateral core still remained held together with the rest of the cube surface. This is because of the bridging effect of the steel fibers which interlocks fibers with the coarse aggregate. The bridging effect of the steel fibers in the HSFRC mix is shown in Figure 4(c).

The failure mode of the NRC and HSFRC beams under flexural loading is shown in Figures 5(a) and 5(b).

It was observed that the NRC beam broke into two parts when it was subjected to flexural loading. However, when the load was put on the HSFRC as shown in Figure 5(b), it withstood the loading. The inclusion of steel fibers, in the 


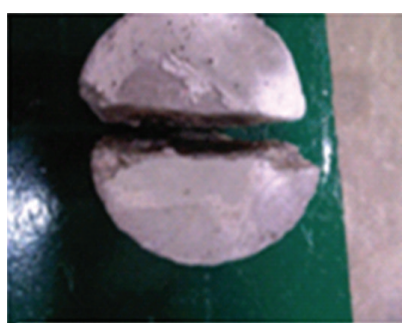

(a)

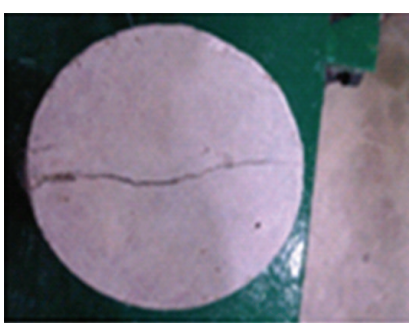

(b)

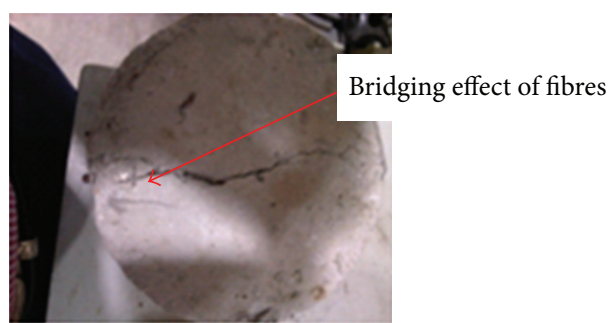

(c)

FIGURE 6: (a) Failure mode of NRC cylinder. (b) Failure mode of HSFRC cylinder. (c) Bridging action of steel fibers in HSFRC cylinder.

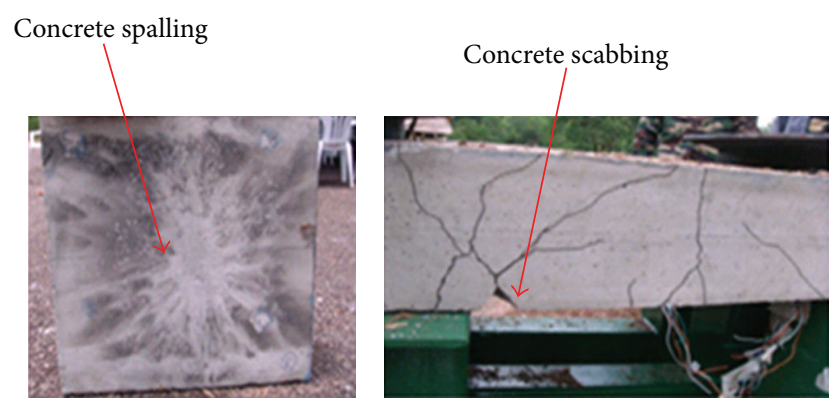

FIGURE 7: Failure mode of NRC panel subjected to blast loading.

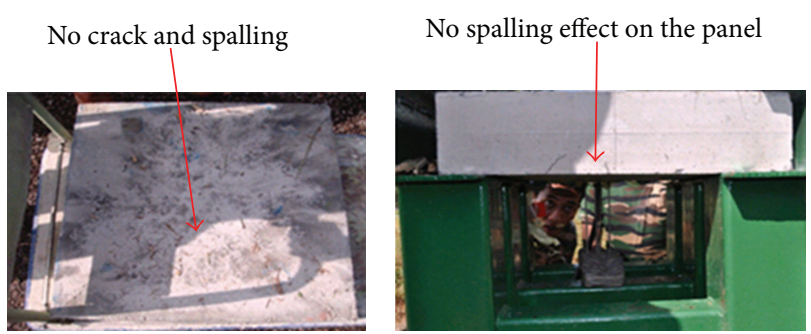

FIGURE 8: Failure mode of HSFRC panel subjected to blast loading.

HSFRC, provides bridging, and dispersing of the stress on macrocracks in the concrete until they slip off the concrete. This bridging effect of steel fibers in the concrete cubes is shown in Figure 5(c).

The failure mode of NRC and HSFRC under tensile loading is shown in Figures 6(a) and 6(b).

The NRC cylinder breaks into two as shown in Figure 6(a), while the HSFRC cylinder was still intact together and had minor cracks. This is because of the bridging action of steel fibers in the concrete mix which prevented the cylinder from breaking apart as shown in Figure 6(c).

3.3. Failure Mode of Hybrid Steel Fibre Reinforced Concrete Panels under Blast Loading. At the end of the blast test, the failure mode of each panel was photographed and the crack lines were marked. The failure mode of NRC and HSFRC which were subjected to air blast loading is shown in Figure 7 and also Figure 8.

From the blast test conducted on the NRC concrete panel it was noticed that spalling (spilling) occurs on the top surface of the NRC concrete panel when it is subjected to blast loading, while scabbing occurs at the bottom part of the panel. This is because when the top surface is subjected to air blast loading, very high pressure wave and impulse were created that transferred through the concrete panel at a very high velocity and air blast loading causes the spalling (spilling) at the top surface of the concrete and scabbing effect on the bottom surface of the panel. This phenomenon happened because of the NRC panel's low resistance against blast loading. On the other hand when the HSFRC panel was subjected to blast loading, it survived the blast with only minor cracks and no spalling effect was shown at the bottom of the panel. This is shown in Figure 8.

HSFRC survived the blast test, because blast overpressure that resulted from the detonation was absorbed by the randomly oriented steel fibers in the hybrid concrete panel which has high energy absorption capability and also high tensile and flexural strength.

3.4. Peak Overpressure. The results for the peak overpressure were obtained by using LabView program. The peak overpressure that resulted from the detonation was $14.8 \mathrm{MPa}$ and it is shown in Figure 9.

These results show that the HSFRC concrete panel is able to withstand up to $14.8 \mathrm{MPa}$ of peak blast overpressure that resulted from $1 \mathrm{~kg}$ of explosive at a distance of $300 \mathrm{~mm}$ as compared with the NRC concrete panel which has failed to resist the peak overpressure resulted from the detonation. This provides evidence that HSFRC has an ability to resist blast loading.

\section{Numerical Simulation}

The simulation works on the NRC and HSFRC panels subjected to blast loading were carried out using ANSYS AUTODYN 2D simulation program. The simulation results were compared with the experimental data. Concrete, air, and also explosive were modeled by using Euler subgrid. A mesh size of $600 \mathrm{~mm} \times 1000 \mathrm{~mm}$ was selected for the model. The element number is $300 \times 500$, resulting in total element number of 150,000 . The $2 \mathrm{D}$ model for simulation model is shown in Figure 10.

The concrete was modeled with RHT material model. This material model was developed by Riedel, Hiermayer, and Thomas (therefore called the RHT model) [9]. This is the 


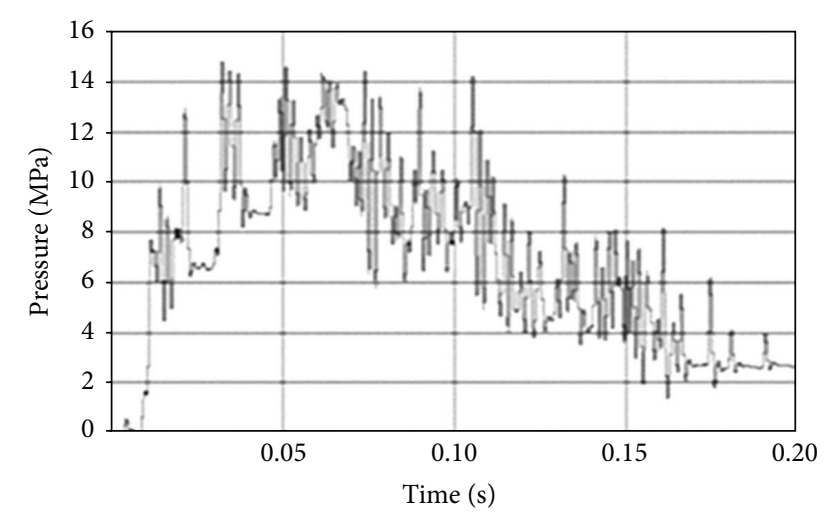

FIGURE 9: Peak overpressure resulted from $1 \mathrm{~kg}$ of plastic explosive at a distance of $300 \mathrm{~mm}$.

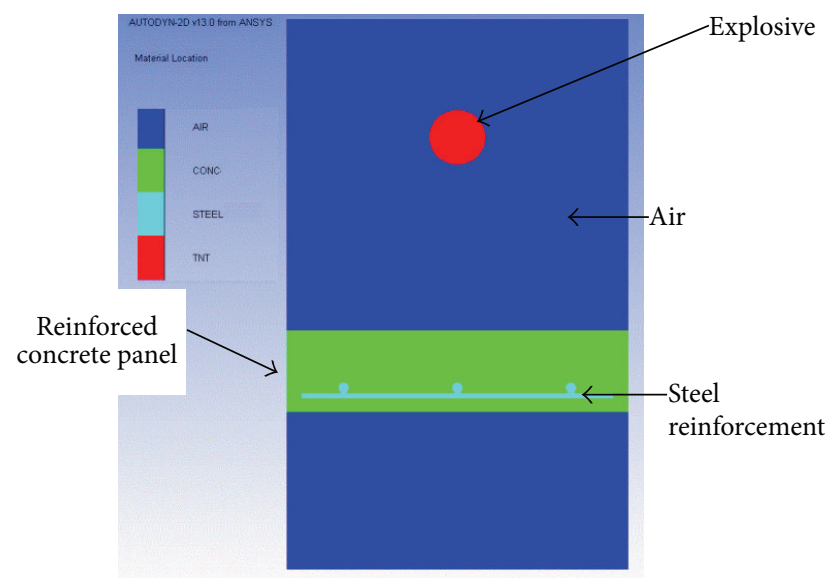

FIGURE 10: 2D model for simulation works.

standard material model for concrete in the material library of AUTODYN that describes the behavior of concrete.

Johnson Cook material model was used to describe the behavior of the steel reinforcement inside the concrete [10]. This is the standard material model for steel reinforcement in the material library of AUTODYN that describes the behavior of steel reinforcement, subjected to explosion. The yield strength for both control mix concrete and also hybrid steel fiber concrete steel bar reinforcement was taken as $460 \mathrm{MPa}$ based on the high strength steel bar materials strength properties obtained from BS 8110: Part 1: 1997 [11].

Air was modeled as an ideal gas. The air density used is $\rho=1.225 \mathrm{~kg} / \mathrm{m}^{3}$ and air initial internal energy used is $2.068 \times$ $10^{5} \mathrm{~kJ} / \mathrm{kg}$ which is obtained from AUTODYN material library. Jones-Wilkins-Lee (JWL) equation of state was used to model the rapid expansion of high explosive detonation of plastic explosive [12]. The material properties of plastic explosive (PE4) were obtained from AUTODYN material library.

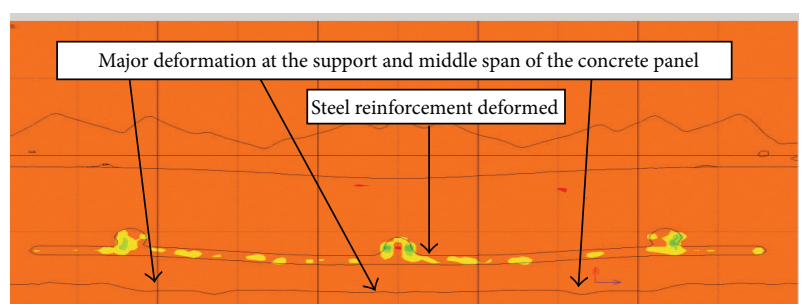

(a)

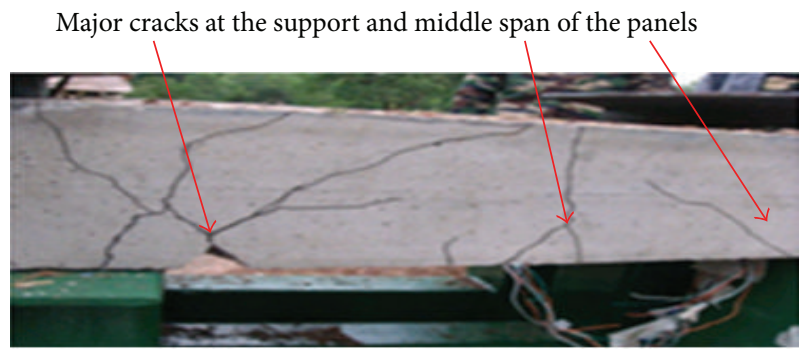

(b)

FIgURE 11: (a) Simulation results for NRC panel. (b) Experiment results for NRC panel.

\section{Simulation Results and Discussion}

5.1. Simulation Results for NRC Panel. The comparison of crack areas that are obtained from simulations with those with experimental test results for NRC panel is shown in Figures 11(a) and 11(b). In the simulation works the crack location on the concrete panels can be identified through the deformation pattern on the concrete panels.

From the simulation results as shown in Figure 11(a) it was shown that there is major deformation on the NRC panel at the support and also midspan of the concrete panel. In addition to this, the steel reinforcement also has deformed or was bent at the centre of the panel. This indicates that there is high possibility of cracks occurring at the deformation area when concrete is deformed. Further to this, the location of the deformed or cracked area is found to be at the same location as seen in the experimental results which are shown in Figure 11(b). Therefore the simulation results agreed well with the experimental work.

5.2. Simulation Results for HSFRC Panel. The simulation and also experimental results for HSFRC panel are shown in Figures 12(a) and 12(b).

From the simulation results as shown, there is a minor deformation near the midspan of the concrete panel. This indicates a high possibility of minor cracks occurring at the deformed area when concrete is deformed. The location of the deformed or cracked area was found to be at the same location as seen in the experimental results. Therefore the simulation results agreed well with the experimental work.

5.3. Peak Overpressure Results. The simulation and experimental results for the peak overpressure at 0.3 meter from the point of blast are shown in Figure 13. 


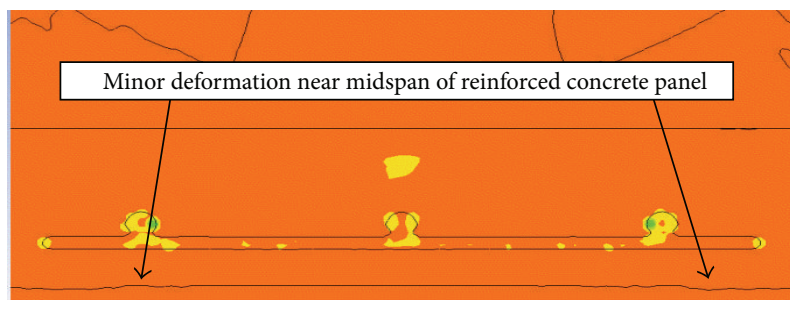

(a)

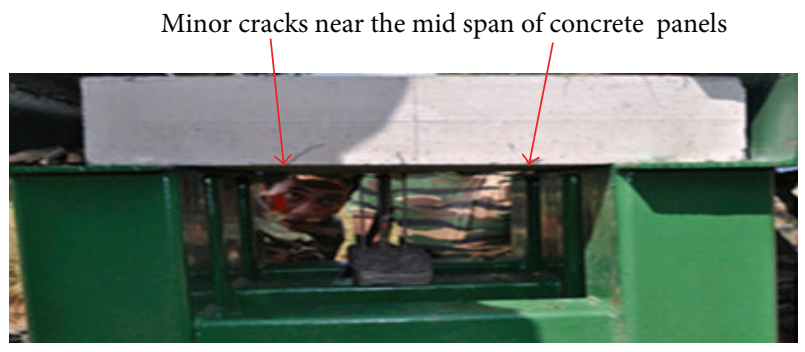

(b)

FIGURE 12: (a) Simulation results for HSFRC panel. (b) Experiment results for HSFRC panel.

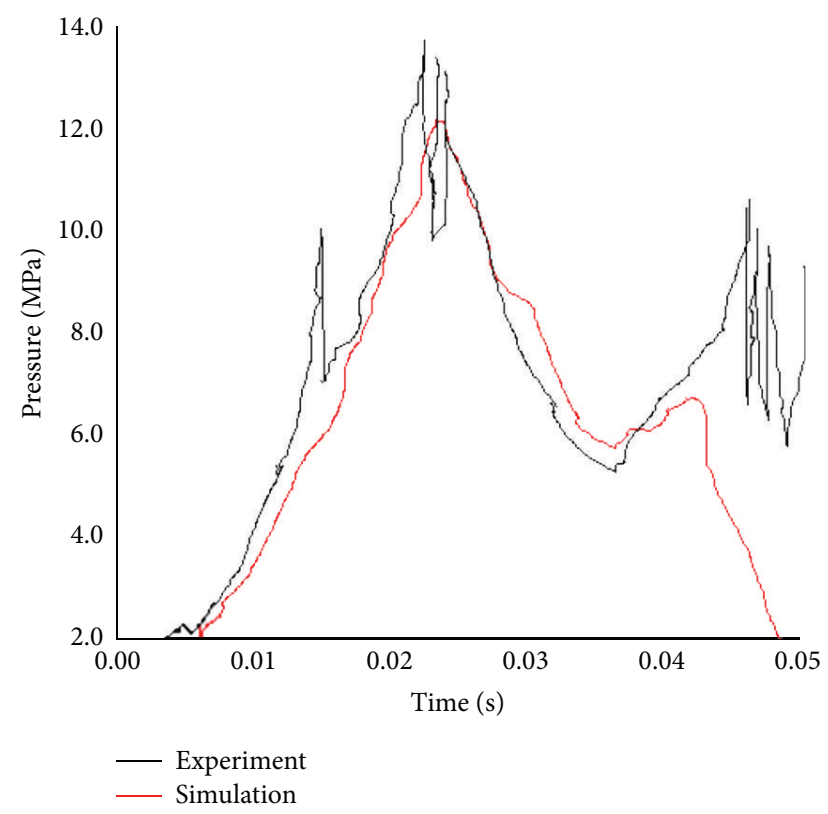

FIGURE 13: Result for peak overpressure resulted from $1 \mathrm{~kg}$ of plastic explosive at 0.3 meter standoff distance.

With reference to Figure 13, it was observed that in the simulation, the recorded peak over pressure is $12.7 \mathrm{MPa}$, while the field blast test result shows the peak overpressure of 14.8 $\mathrm{MPa}$. The results show a difference of only $14.86 \%$ for pressure between simulation and experimental results. Therefore the simulation result agreed well with the experiment.

\section{Conclusions}

The researcher investigated the field blast test on performance of NRC and also HSFRC concrete panel subjected to air blast loading. In addition, a simulation modelling using ANSYS AUTODYN was also performed to validate the experimental data. The main conclusions that can be derived from the research are as follows.

(1) The incorporation of hybrid steel fibers in the normal concrete mix improved the mechanical properties of the concrete mix.

(2) Hybrid steel fibers with the combination of $70 \%$ long and $30 \%$ short steel fibers at volume fraction of $1.5 \%$ in concrete mix of (HSFRC) provide resistance towards the blast loading as compared with normal concrete mix without fibers (NRC). It was observed that incorporating the hybrid steel fibers has reduced the effect of spalling and scabbing on the concrete panel.

(3) The simulation results using AUTODYN software were found to be close with experiment results. Therefore the results have been validated using the experimental data.

\section{Acknowledgment}

The authors wish to gratefully acknowledge the support from the Civil Engineering Laboratory Technicians of Universiti Pertahanan Nasional Malaysia for providing assistance for this research project.

\section{References}

[1] P. A. Buchan and J. F. Chen, "Blast resistance of FRP composites and polymer strengthened concrete and masonry structures-A state-of-the-art review," Composites B, vol. 38, no. 5-6, pp. 509522, 2007.

[2] Y. Mohammadi, R. Carkon-Azad, S. P. Singh, and S. K. Kaushik, "Impact resistance of steel fibrous concrete containing fibres of mixed aspect ratio," Construction and Building Materials, vol. 23, no. 1, pp. 183-189, 2009.

[3] D. E. Otter and A. E. Naaman, "Strain rate effect on compressive properties of fiber reinforced concrete," in Proceedings of the International Symposium on Fibre Reinforced Concrete, vol. 2, pp. 225-235, Madras, India, December 1987.

[4] P. K. Nagarkar and S. K. Tambe, "Study of fiber reinforced concrete," in Proceedings of the International Symposium on Fibre Reinforced Concrete, vol. 2, p. 130, Madras, India, December1987.

[5] V. S. Gopalaratnam and S. Shah, "Failure mechanism and fracture of fibre reinforced concrete," in Fibre Reinforced ConcreteProperties and Application, pp. 1-25, American Concrete Institute, Detroit, Mich, USA, 1987.

[6] P. Tadepalli, Y. Mo, T. Hsu, and J. Vogel, "Mechanical properties of steel fiber reinforced concrete beams," in Proceedings of the ASCE Structures Congress, pp. 1039-1048, May 2009.

[7] Y. Mohammadi, S. P. Singh, and S. K. Kaushik, "Properties of steel fibrous concrete containing mixed fibres in fresh and hardened state," Construction and Building Materials, vol. 22, no. 5, pp. 956-965, 2008.

[8] A. Bentur and S. Mindess, Fibre Reinforced Cementitious Composites, Elsevier Science, New York, NY, USA, 1990.

[9] Riedel, "RHT concrete model," 2010, http://www.kxcad.net/ ansys/autodyn/material/RHT. 
[10] U. Nyström and K. Gylltoft, "Numerical studies of the combined effects of blast and fragment loading," International Journal of Impact Engineering, vol. 36, no. 8, pp. 995-1005, 2009.

[11] British Standard Institution, BS, 8110: Part 1: Code of Practice for Design and Construction, British Standard Institution, London, UK, 1997.

[12] U. Nystrom, Numerical simulation of fiber reinforced concrete subjected to blast impact [M.S. thesis], Chalmer University of Technology, Goteborg, Sweden, 2008. 

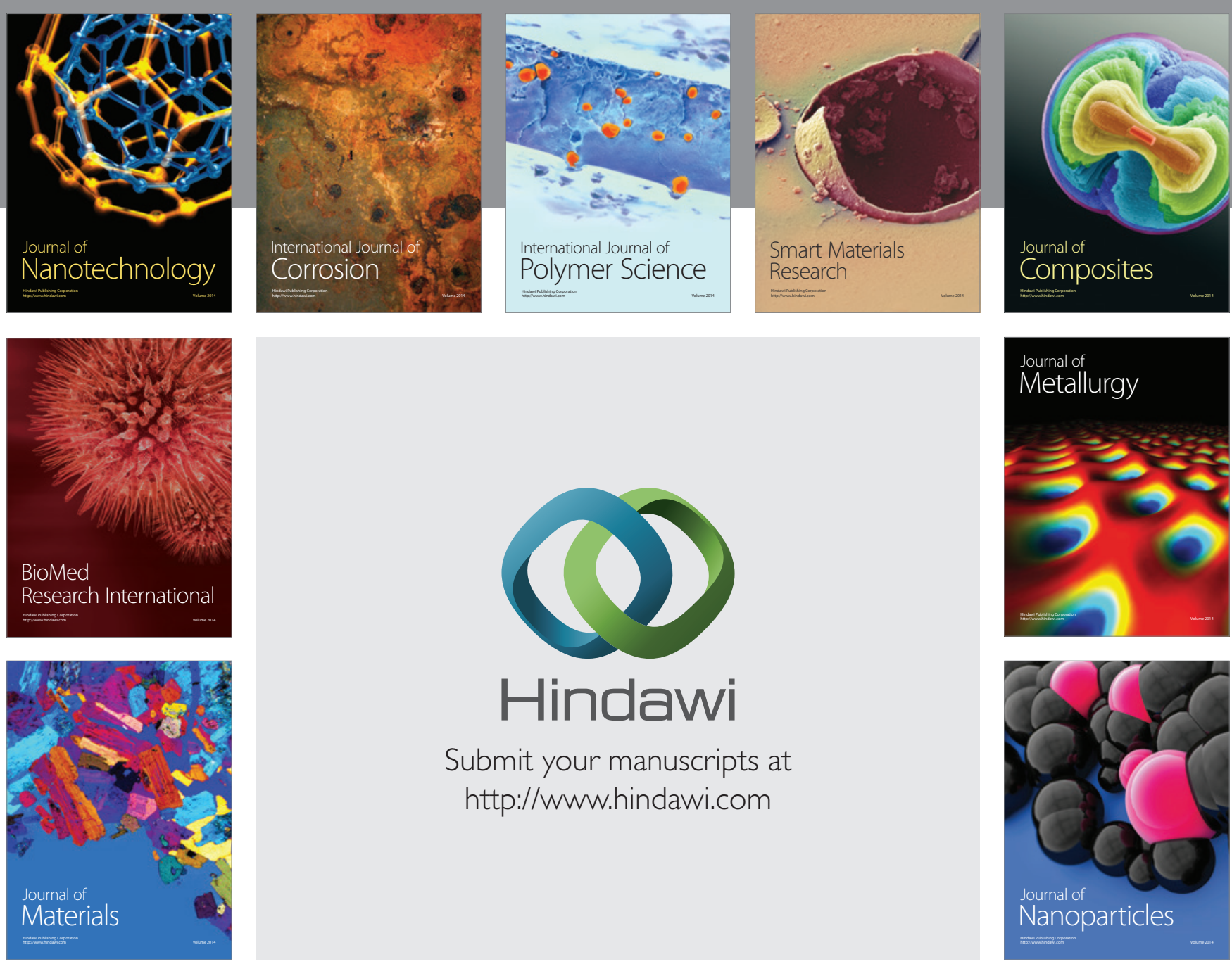

Submit your manuscripts at http://www.hindawi.com
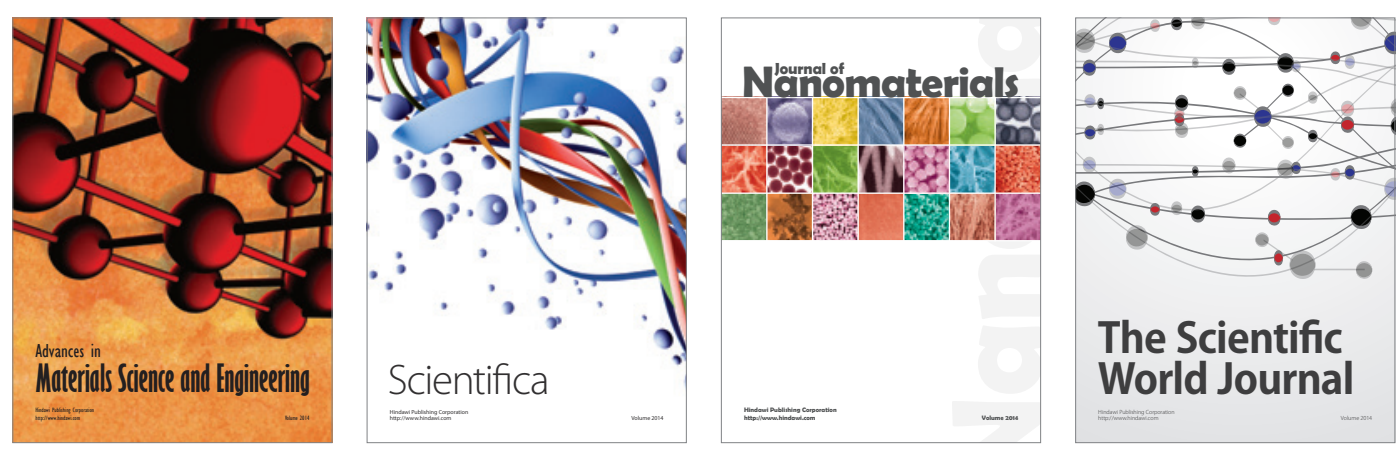

\section{The Scientific World Journal}
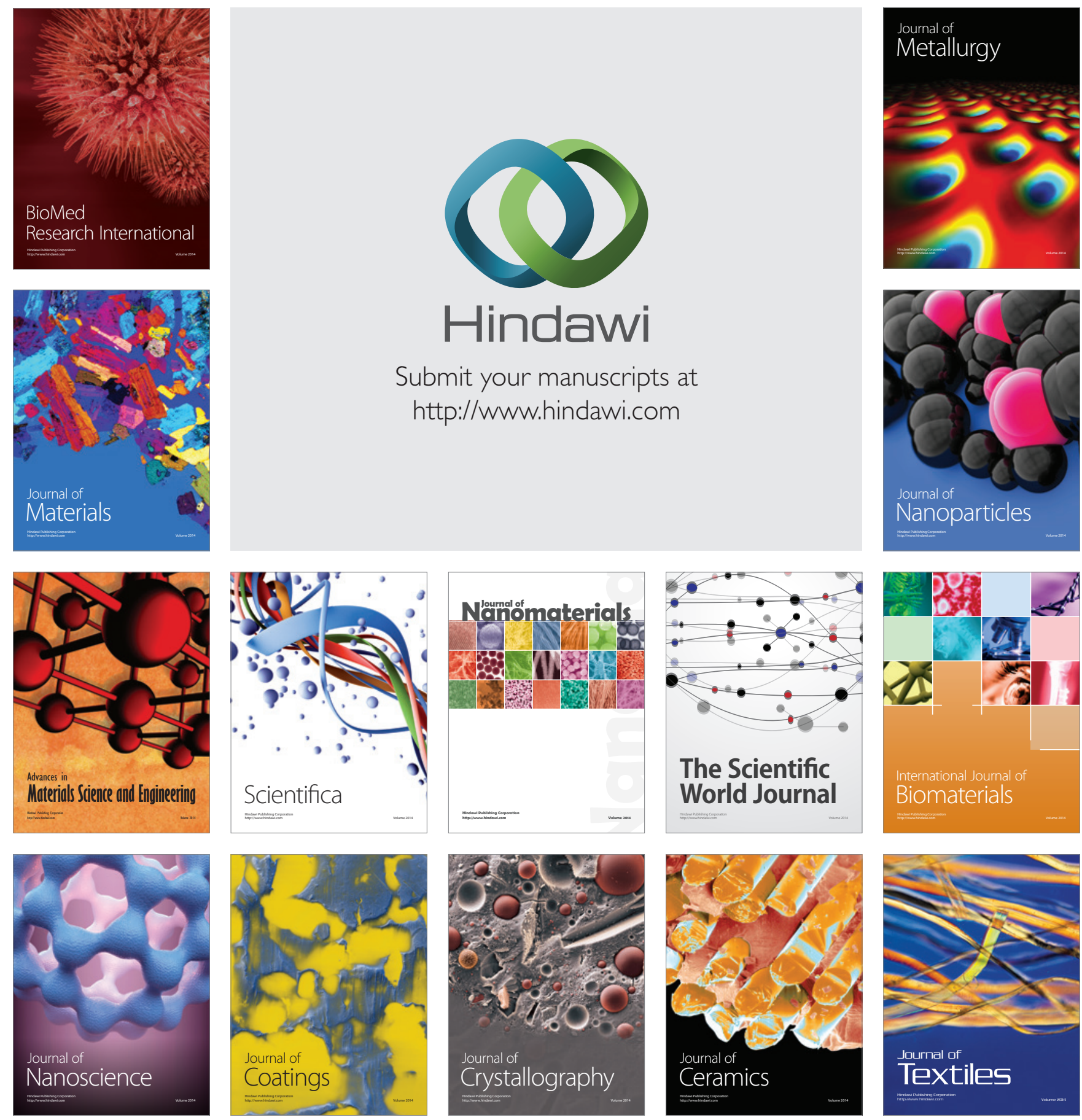